\title{
New approaches for the management of bipolar disorder: role of sublingual asenapine in the treatment of mania
}

This article was published in the following Dove Press journal:

Neuropsychiatric Disease and Treatment

23 May 2013

Number of times this article has been viewed

\author{
Calvert G Warren' \\ Steven L Dubovsky ${ }^{1,2}$ \\ 'Department of Psychiatry, State \\ University of New York at Buffalo, \\ Buffalo, NY, USA; '2Departments \\ of Psychiatry and Medicine, University \\ of Colorado, Boulder, CO, USA
}

Correspondence: Steven L Dubovsky State University of New York at Buffalo, 462 Grider St Room I I82, Buffalo, NY I 4215, USA

$\mathrm{Tel}+\mathrm{l} 7168985940$

Email dubovsky@buffalo.edu

\begin{abstract}
Bipolar disorder is a prevalent disorder that tends to become progressive without treatment and with inadequate treatment. Second generation (atypical) antipsychotic drugs have increasingly been used as adjunctive treatment or monotherapy for mania, but they have the potential for significant adverse effects and their role in maintenance treatment remains unclear. Asenapine is a new atypical antipsychotic medication formulated in a sublingual preparation that has been studied for mania but not maintenance therapy. Evidence indicating efficacy, adverse effects, and potential benefits and drawbacks of using asenapine in the treatment of bipolar disorder based on currently available published data are summarized.
\end{abstract}

Keywords: bipolar disorder, antipsychotic drug, mania, maintenance, sublingual

\section{Management issues in bipolar disorder}

Bipolar disorder is a chronic or recurrent condition characterized by episodes of depression alternating or mixed with mania or hypomania. Bipolar disorder is associated with more disability than cancer, epilepsy, and Alzheimer's disease. ${ }^{1,2}$ People with bipolar disorder have high rates of suicide, substance use, obesity, heart disease, smoking, and sedentary lifestyle, with consequent increased morbidity and mortality. ${ }^{3}$ Between $20 \%$ and $28 \%$ of depressed patients taking antidepressants in primary care practices have repeatedly been found to have clear-cut bipolar disorder; the diagnosis is rarely made by the primary care physician ${ }^{48}$ although morbidity and mortality are high. In 2009 the direct and indirect costs of bipolar I and bipolar II disorder were $\$ 30.7$ and $\$ 120.3$ billion, in USD respectively. ${ }^{9}$

The combined prevalence of bipolar I (episodes of mania and hypomania) and bipolar II (hypomania only) disorder has generally been estimated to range roughly between $0.5 \%$ and $2 \%{ }^{10-15}$ However, a number of investigators have suggested that bipolar disorder comprises a larger spectrum of conditions associated with clinically significant morbidity. ${ }^{16,17}$ Subsyndromal or subthreshold forms of bipolar disorder include patients with hypomanic symptoms without sufficient duration, a sufficient number of symptoms, or enough obvious impairment, to qualify for a formal bipolar diagnosis. ${ }^{18,19}$ Including subthreshold syndromes increases the lifetime prevalence of bipolar disorders to somewhere between $4.4 \%$ and $6.4 \%{ }^{2,12}$ Although such syndromes appear to be attenuated, they have a high risk of suicide attempts, comorbidity with anxiety, impulse control and substance use disorders, and conversion to frank bipolar disorder, ${ }^{20}$ as well as similar degrees of role impairment to bipolar I and II disorder. $^{21}$ 
Depression is the most common complaint of patients with bipolar mood disorders, and many of these patients are treated with antidepressants, which have not been found to be more effective than placebo for bipolar depression..$^{22,23}$ Although the issue has been debated, antidepressants appear to have the potential to induce hypomania or mania and to increase the rate of recurrence of depression, especially if any residual hypomanic symptoms are present. ${ }^{7,23,24}$ It is often more effective to stabilize mood (ie, to prevent further manic and depressive recurrences) than to continue antidepressant treatment for any particular depressive episode for too long.

This goal can be achieved with mood stabilizers, which are defined as treatments that both treat and prevent recurrences of mania and depression. ${ }^{25}$ The gold standard mood stabilizer against which other treatments are compared is lithium, ${ }^{25}$ which has advantages of once daily dosing and a clear correlation of serum level with clinical response. However, laboratory monitoring for hypothyroidism, hyperparathyroidism and possible nephropathy is necessary, and side effects such as weight gain, cognitive impairment, tremor and gastrointestinal side effects are often troublesome. Like carbamazepine, valproate has been thought to be more effective than lithium for rapid cycling, ${ }^{26,27}$ although some studies find lithium to be effective for this state. ${ }^{28}$ Adverse effects of valproate that are particularly bothersome include weight gain, sedation, and polycystic ovarian syndrome. Carbamazepine is effective acutely and prophylactically for mania and can be useful for depression, especially in combination with lithium. ${ }^{28-30}$ However, in addition to common side effects such as rash, ataxia, sedation and hyponatremia, the rare $(2 / 525,000)$ risk of bone marrow suppression is daunting to some patients. Other anticonvulsants have been investigated as mood stabilizers but only lamotrigine is approved as maintenance therapy, and that medication appears more useful in the treatment of bipolar depression than mania. ${ }^{31}$

All antipsychotic drugs that have been studied have been found to be effective for mania, ${ }^{32-34}$ and atypical antipsychotic drugs have been promoted widely for maintenance therapy. However, randomized trials supporting this application have involved patients with uncomplicated mood disorders without the kind of comorbidity that is common in actual practice. ${ }^{35}$ In addition, not many antipsychotic drugs have been studied for this indication, and adverse effects, especially with chronic treatment, are causes for concern. ${ }^{36-41}$

Like many illnesses, bipolar disorder evolves over time, with later episodes becoming more severe, complex and autonomous than earlier episodes. Increasing clinical complexity of bipolar disorder appears to be associated with increasing pathophysiologic complexity. Whereas a single mood stabilizer may be effective for less complicated forms of the illness, more complicated symptom pictures (eg, mixtures of depressive and hypomanic symptoms or rapid mood swings) may require combinations of treatments with different actions. ${ }^{42-47}$ Yet most clinical trials have been of monotherapy, with a few studies of addition of olanzapine, quetiapine, or ziprasidone to lithium or valproate in patients without comorbidity, complexity, or suicidality, ${ }^{48-50}$ leaving trial and error as the primary method of finding the right combination treatment in more complicated clinical settings. New agents that may be more effective for complex presentations of bipolar disorder, those that have fewer interactions with other medications used for this condition, and agents that can treat bipolar depression without destabilizing the mood disorder are therefore urgently needed. This review considers whether asenapine presents any advantages.

\section{Review of pharmacology, mode of action, and pharmacokinetics of asenapine}

Asenapine, the ninth atypical antipsychotic agent to be released in the USA,${ }^{51}$ is approved in the USA for the acute monotherapy or adjunctive treatment of manic and mixed episodes and schizophrenia. ${ }^{52}$ Pharmacologically, it is a dibenzo-oxepino pyrrole drug with mixed serotonin (5-HT)dopamine (D) antagonist activity. It exhibits high affinity for 5-HT1B, 5-HT2A, 5-HT2B, 5-HT2C, 5-HT5-7, D1-4, histamine 1 (H1), alpha1- and alpha2-adrenergic receptors; it has moderate affinity for $\mathrm{H} 2$ receptors but no significant affinity for cholinergic muscarinic receptors; it is also a 5-HT1A partial agonist. ${ }^{53}$

Dopamine D2 receptor blockade has been considered necessary for treatment of psychosis, but blockade of serotonin 5-HT2A receptors and effects on glutaminergic, GABAergic, and nicotinic cholinergic neurotransmission have also been implicated in the mechanisms of action of antipsychotic drugs, as have alterations in cell signaling and gene expression. ${ }^{54} \mathrm{In}$ contrast to the first generation antipsychotic drugs (neuroleptics), second generation (atypical) antipsychotic drugs such as asenapine are characterized by less D2 and greater 5-HT2 antagonism, with reduced but not absent neurological side effects and no greater effectiveness. ${ }^{55}$

Asenapine is only available as a sublingual, rapidly dissolving formulation that exposes the drug only to salivary enzymes and bypasses first pass metabolism. ${ }^{53,56}$ Asenapine absorption is rapid from the oral cavity into the 
mucosal tissue. Dissolved drug in the oral cavity reaches equilibrium with the mucosal membrane within minutes, with slower movement out of mucosal tissue into the systemic circulation. Bioavailability is 35\% with sublingual administration but $<2 \%$ if asenapine is ingested; because absorption is also decreased in the presence of food or liquid, oral intake must be avoided for 10 minutes after taking the medication. At doses above the saturation solubility, bioavailability becomes dependent on the distribution equilibrium and also on contact time in the mouth. ${ }^{57}$ Compared with the sublingual route, asenapine exposure is $24 \%$ higher with buccal and supralingual administration administration. ${ }^{58}$ However, the latter routes convey a risk of tooth decay.

Time to peak plasma concentration is $0.5-1.5$ hours. The volume of distribution is around $20-25 \mathrm{~L} / \mathrm{kg}$, with $95 \%$ protein binding. Metabolism is by oxidation via cytochrome (CYP450) 1A2, followed by glucuronidation by UGT1A4. ${ }^{53}$ Terminal elimination half-life is approximately 24 hours. Nevertheless, dosing is usually twice daily.

\section{Efficacy studies}

In two identically designed, industry-sponsored, multicenter, 3-week, double-blind controlled trials, 488 patients (mean age 39 years) with a manic or mixed episode were randomly assigned to asenapine (mean dose $18 \mathrm{mg}$ /day), olanzapine (mean dose $16 \mathrm{mg} /$ day), or placebo. ${ }^{59-61}$ Significantly fewer subjects discontinued olanzapine than asenapine or placebo. Both active medications produced significantly greater reductions in Young Mania Rating Scale (YMRS) scores than placebo (least squares mean YMRS decrease at 3 weeks 10.8 with asenapine (effect size 0.45 ), 12.6 with olanzapine (effect size 0.70), 5.5 with placebo). A 9-week blinded extension of the two acute studies ${ }^{59,62}$ continued 504 patients on asenapine or olanzapine, while placebo patients were given asenapine and included only in a safety analysis. At the end of the extension, asenapine was noninferior to olanzapine for YMRS scores. Adverse effects were similar except for more weight gain with olanzapine.

A series of 11 consecutively admitted manic inpatients (mean age 68 years) were openly treated for 4 weeks with asenapine monotherapy (mean dose $20 \mathrm{mg}$ /day). ${ }^{63}$ There was a significant decrease in mean YMRS scores $(-21.4)$ by the end of the trial. The greatest improvement was in "motor activity-energy" and "thought content," items, consistent with an antipsychotic and sedative effect.

In another industry-sponsored and conducted, multicenter randomized trial, ${ }^{64} 326$ patients with a manic or mixed episode of 3 months or less duration taking lithium and/or valproate for at least 2 weeks were assigned in a blinded manner to addition of asenapine (mean dose, 12-13 mg/day) or placebo; 204 were treated for 3 weeks, 116 were treated for 3 months, and 77 enrolled in and 34 completed a one-year extension. ${ }^{64}$ About half of patients received adjunctive lorazepam and around 38\% had an adjunctive hypnotic. Least squares mean reduction in YMRS scores was significantly greater with asenapine than placebo at week 3 (10.3 versus 7.9$)$ and week 12 (12.7 versus 9.3), with small effect sizes (0.24 and 0.33 , respectively). There was no difference in YMRS score changes between addition of asenapine and placebo at the end of the extension.

\section{Safety and tolerability}

Of the 308 patients who completed the 9 -week trial mentioned earlier, 218 were enrolled in and 133 completed an extension for another 40 weeks to examine longer-term safety and tolerability. ${ }^{65}$ Adverse events occurring twice as frequently with asenapine as placebo, and in $>10 \%$ of subjects, included depression, dizziness, nausea, parkinsonism, tremor, and constipation. The number needed to harm for clinically significant weight gain with asenapine was 7 . Adverse events occurring at least $5 \%$ of the time and twice as common with asenapine than placebo in the controlled add-on trial included sedation, depression, irritability, oral hypoesthesia, dyskinesia, and weight gain. ${ }^{64}$ In the published trial of elderly manic patients, adverse effects included a rash in one patient, peripheral edema in one patient, and oversedation in three patients. ${ }^{63}$

In a systematic review and exploratory meta-analysis of studies in schizophrenia or bipolar disorder of asenapine, iloperidone, lurasidone, and paliperidone,${ }^{66}$ asenapine was found to be statistically significantly more likely than placebo to be associated with a $7 \%$ or greater weight gain in short-term trials ( 5 trials, $\mathrm{n}=1360$, relative risk $[\mathrm{RR}]=4.09,95 \%$ confidence interval $[\mathrm{CI}] 2.25,7.43$, number needed to harm $[\mathrm{NNH}]=17$ ). A clinically small but statistically significant increase in glucose levels $(-3.95 \mathrm{mg} / \mathrm{dL})$ was also reported during short-term treatment. Increased total cholesterol was statistically significantly more likely than placebo during long-term treatment with asenapine, but the increase was small $(+6.53 \mathrm{mg} / \mathrm{dL})$.

In the treatment of schizophrenia, common adverse events (with frequency of occurrence) of asenapine include somnolence ( $13 \%$ to $24 \%$ ), insomnia ( $6 \%$ to $16 \%$ ), extrapyramidal symptoms $(6 \%$ to $12 \%)$, headache $(12 \%)$, akathisia ( $4 \%$ to $11 \%$; dose related), dizziness (3\% to $11 \%$ ), hypertriglyceridemia $(13 \%$ to $15 \%)$, increased glucose $(5 \%$ to $7 \%)$, increased cholesterol ( $8 \%$ to $9 \%)$, increased appetite $(\leq 4 \%)$, weight 
gain $(2 \%$ to $15 \%)$, constipation ( $4 \%$ to $7 \%)$, vomiting $(4 \%$ to $7 \%)$, sialorrhea $(\leq 4 \%)$, increased creatine kinase $(6 \%$ to $11 \%$ ), peripheral edema (3\%), hypertension ( $2 \%$ to $3 \%)$, mouth hypoesthesia ( $4 \%$ to $7 \%$ ), xerostomia (1\% to $3 \%$ ), toothache (3\%), abdominal discomfort (3\%), abnormal taste $(3 \%)$, prolactinemia ( $2 \%$ to $3 \%)$, arthralgias (3\%), fatigue (3\% to $4 \%$ ), anxiety (4\%), depression ( $2 \%)$, irritability ( $1 \%$ to $2 \%$ ), and extremity pain $(2 \%) .{ }^{54}$ In addition, in postmarketing experience a few cases have been reported of severe hypersensitivity reactions, bradycardia, dysarthria, glossodynia, hyponatremia, neuroleptic malignant syndrome, thrombocytopenia, QTc prolongation and neutropenia. ${ }^{54}$

No dosage adjustment is necessary for patients with mild to moderate hepatic impairment, ${ }^{53}$ however, asenapine is not recommended for patients with severe hepatic impairment. ${ }^{67}$ Asenapine is a substrate for CYP1A2, and inhibitors of this enzyme such as fluvoxamine may increase the asenapine AUC. Asenapine weakly inhibits CYP2D6, which has resulted in increased exposure to concomitant paroxetine but not desipramine. ${ }^{53}$

\section{Patient focused perspectives}

Few data are available about quality of life and patient satisfaction with the use of asenapine in bipolar disorder. Sublingual administration is appealing to patients who have difficulty swallowing pills, especially older patients and children. However, twice daily dosing, the need to avoid food and liquids for at least 10 minutes before and after administration, and low bioavailability if the tablet is swallowed increase the likelihood of nonadherence and improper administration. ${ }^{68}$ Nonadherence by inpatients who are observed taking the medication can be easy if the patients swallow it instead of keeping it under their tongues.

\section{Conclusions and place in therapy}

Like other atypical antipsychotic drugs, asenapine antagonizes D2 and 5-HT2 receptors. This combination of actions may reduce extrapyramidal side effects, although a large nonindustry sponsored study found no meaningful difference between a neuroleptic and other atypical antipsychotics. ${ }^{55}$ Weight gain and oversedation are somewhat less frequent than with other medications in this class, whereas oral side effects such as hypoesthesia, a bad taste, and xerostomia are more common. Although it has been suggested that the additional receptor actions of asenapine might make it more effective for some psychotic symptoms such as hallucinations, there is no empirical support for this contention and asenapine does not appear to be any more (or less) effective than other atypical antipsychotics. All of the experimental data on therapeutic effects of asenapine are for mania. There is as yet insufficient evidence that this or any other antipsychotic drug has a primary role in maintenance therapy of nonpsychotic bipolar disorder.

The sublingual formulation of asenapine could be appealing to a group of patients who have difficulty swallowing pills, and it could be an early choice for some elderly patients. However, even though the pivotal trials enrolled acutely manic patients, its usefulness is limited in severely ill patients who are too agitated to be able to keep the medication in their mouths without swallowing it, even if they would be able to swallow a pill.

Atypical antipsychotic drugs may be useful as adjuncts in the maintenance therapy of bipolar disorder, but there is insufficient research to determine the precise role of this class of medication in maintenance treatment of nonpsychotic patients. To the extent that these medications can be helpful, the choice of asenapine would be dictated by the unique aspects of its administration rather than any demonstrated inherent properties of the drug. There are not enough data to indicate any preferential role of asenapine in the long-term treatment of bipolar disorder.

\section{Disclosure}

Dubovsky has received research funding from Otsuka, Janssen, Pfizer, Lilly, Merck, Sunovion, and Sumitomo. Dr Warren reports no conflicts of interest in this work.

\section{References}

1. Kleinman L, Lowin A, Flood E, et al. Costs of bipolar disorder. Pharmacoeconomics. 2003;21:601-622.

2. Merikangas KR, Jin R, He J-P, et al. Prevalence and correlates of bipolar spectrum disorder in the World Mental Health Survey Initiative. Arch Gen Psychiatry. 2011;68:241-251.

3. Jansen K, da Costa Ores L, de Azvedo Cardoso T, et al. Prevalence of episodes of mania and hypomania and associated comorbidities among young adults. J Affective Disord. 2011;130:328-333.

4. Hirschfeld RM, Cass AR, Holt DC, Carlson CA. Screening for bipolar disorder in patients treated for depression in a family medicine clinic. J Am Board Fam Pract. 2005;18:233-239.

5. Das AK, Olfson M, Gameroff MJ, et al. Screening for bipolar disorder in a primary care practice. JAMA. 2005;293:956-963.

6. Olfson M, Das AK, Gameroff MJ, et al. Bipolar depression in a lowincome primary care clinic. Am J Psychiatry. 2005;162:2146-2151.

7. Shi L, Thiebaud P, McCombs JS. The impact of unrecognized bipolar disorders for patients treated for depression with antidepressants in the fee-for-services California Medicaid (Medi-Cal) program. J Affect Disord. 2004;82:373-383.

8. Dubovsky SL, Leonard K, Griswold K, et al. Bipolar disorder is common in depressed primary care patients. Postgraduate Medicine. 2011; 123:129-133.

9. Dilsaver SC. An estimate of the minimum economic burden of bipolar I and II disorders in the United States: 2009. J Affective Disord. 2011;129: 79-83. 
10. Pini S, de Queiroz V, Pagnin D, et al. Prevalence and burden of bipolar disorders in European countries. Eur Neuropsychopharmacol. 2005; $14: 425-434$.

11. Dunner DL. Clinical consequences of under-recognized bipolar spectrum disorder. Bipolar Disord. 2003;5:456-463.

12. Judd LL, Akiskal HS. The prevalence and disability of bipolar spectrum disorders in the US population: re-analysis of the ECA database taking into account subthreshold cases. J Affective Disord. 2003;73: 133-146.

13. Bauer M, Pfennig A. Epidemiology of bipolar disorders. Epilepsia 2005:46.

14. Weissman MM, Bland RC, Canino GJ, et al. Cross-national epidemiology of major depression and bipolar disorder. JAMA. 1996;276:293-299.

15. Grant BF, Stinson FS, Hasin DS, et al. Prevalence, correlates, and comorbidity of bipolar I disorder and axis I and II disorders: results from the National Epidemiologic Survey on Alcohol and Related Conditions. J Clin Psychiatry. 2005;66:1205-1215.

16. Akiskal HS. The prevalent clinical spectrum of bipolar disorders: Beyond DSM-IV. J Clin Psychopharmacology. 1996;16(Suppl 2):4S-14S.

17. Angst J, Azorin JM, Bowden CL, et al. Prevalence and characteristics of undiagnosed bipolar disorders in patients with a major depressive episode. Arch Gen Psychiatry. 2011;68:791-799.

18. Akiskal HS, Bourgeois ML, Angst J, et al. Re-evaluating the prevalence of and diagnostic composition within the broad clinical spectrum of bipolar disorders. J Affective Disord. 2000;59(Suppl 1):S5-S30.

19. Angst J, Gamma A, Benazzi F, et al. Toward a re-definition of subthreshold bipolarity: epidemiology and proposed criteria for bipolar-II, minor bipolar disorders and hypomania. J Affective Disord. 2003;73: 133-146.

20. Angst J, Cui L, Swendsen J, et al. Major depressive disorder with subthreshold bipolarity in the National Comorbidity Survey Replication. Am J Psychiatry. 2010;167:1194-1201.

21. Merikangas KR, Akiskal HS, Angst J, et al. Lifetime and 12-month prevalence of bipolar spectrum disorder in the National Comorbidity Survey replication. Arch Gen Psychiatry. 2007;64:543-552.

22. Sachs GS, Nierenberg AA, Calabrese JR, et al. Effectiveness of adjunctive antidepressant treatment for bipolar depression. $N$ Engl J Med. 2007;356:1711-1722.

23. Ghaemi SN, Hsu DJ, Soldani F, Goodwin FK. Antidepressants in bipolar disorder: the case for caution. Bipolar Disord. 2003;5:421-433.

24. Schneck CD, Miklowitz DJ, Miyahara S, et al. The prospective course of rapid cycling bipolar disorder: findings from the STEP-BD. Am J Psychiatry. 2008;165:370-377.

25. Bauer M, Mitchner L. What is a "mood stabilizer"? An evidence-based response. Am J Psychiatry. 2004;161:3-18.

26. Ettinger AB. Psychotropic effects of antiepileptic drugs. Neurology. 2006;67:1916-1925.

27. McElroy SL, Keck PE, Stanton SP, et al. A randomized comparison of divalproex oral loading versus haloperidol in the initial treatment of acute psychotic mania. J Clin Psychiatry. 1996;57:142-146.

28. Okuma T, Yamashita I, Takahashi R, et al. Comparison of the antimanic efficacy of carbamazepine and lithium carbonate by double-blind controlled study. Pharmacopsychiatry. 1990;23:143-150.

29. Kramlinger KG, Post RM. The addition of lithium to carbamazepine: antidepressant efficacy in treatment-resistant depression. Arch Gen Psychiatry. 1989;46:794-800.

30. Weisler RH, Hirschfeld R, Cutler AJ, et al. Extended-release carbamazepine capsules as monotherapy in bipolar disorder: pooled results from two randomised, double-blind, placebo-controlled trials. CNS Drugs. 2006;20:219-231.

31. Popovic D, Reinares M, Amann B, Salamero M, Vieta E. Number needed to treat analyses of drugs used for maintenance treatment of bipolar disorder. Psychopharmacology. 2011;213:657-667.

32. Kim E, You M, Pikalov A, Van-Tran Q, Jing Y. One-year risk of psychiatric hospitalization and associated treatment costs in bipolar disorder treated with atypical antipsychotics: a retrospective claims database analysis. BMC Psychiatry. 2011;11:6.
33. McIntyre RS, Brecher M, Paulsson B, Huizar K, Mullen J. Quetiapine or haloperidol as monotherapy for bipolar mania- a 12-week, double-blind, randomised, parallel-group, placebo controlled trial. Eur Neuropsychopharmacol. 2005;15:573-585.

34. Dubovsky SL. Clinical Guide to Psychotropic Medications. New York: WW Norton; 2005.

35. Tohen M, Calabrese JR, Sachs G, et al. Randomized, placebocontrolled trial of olanzapine as maintenance therapy in patients with bipolar I disorder responding to acute treatment with olanzapine. Am J Psychiatry. 2006;163:247-256.

36. Alvarez PA, Pahissa J. QT alterations in psychopharmacology: proven culprits and suspects. Curr Drug Saf. 2010;5:97-104.

37. American Diabetes Association; American Psychiatric Association; American Association of Clinical Endocrinologists; North American Association for the Study of Obesity. Consensus development conference on antipsychotic drugs and obesity and diabetes. Diabetes Care. 2004;27:596-601.

38. Edwards SJ, Smith CJ. Tolerability of atypical antipsychotics in the treatment of adults with schizophrenia or bipolar disorder: a mixed treatment comparison of randomized controlled trials. Clin Ther. 2009; 31(Pt 1):1345-1359.

39. Gothelf D, Falk B, Singer P, et al. Weight gain associated with increased food intake and low habitual activity levels in male adolescent schizophrenic inpatients treated with olanzapine. Am J Psychiatry. 2002;159:1055-1057.

40. Heinrich TW, Biblo LA, Schneider J. Torsades de pointes associated with ziprasidone. Psychosomatics. 2006;47:264-268.

41. Hennessy S, Bilker WB, Knauss JS, et al. Cardiac arrest and ventricular arrhythmia in patients taking antipsychotic drugs: cohort study using administrative data. BMJ. 2002;325:107-110.

42. Coryell W, Endicott J, Maser JD, et al. The likelihood of recurrence in bipolar affective disorder: the importance of episode recency. $J$ Affect Disord. 1995;33:201-206.

43. Gallagher P, Malik N, Newham J, et al. Antiglucocorticoid treatments for mood disorders. Cochrane Database Syst Rev. 2008;2:1-34.

44. Gitlin M. Treatment resistant bipolar disorder. Mol Psychiatry. 2006;11:227-240.

45. Kowatch RA, Sethuraman G, Hume JH, Kromelis M, Weinberg WA. Combination pharmacotherapy in children and adolescents with bipolar diosrder. Biol Psychiatry. 2003;53:978-984.

46. Post RM, Altshuler L, Frye M, et al. Rate of switch in bipolar patients prospectively treated with second generation antidepressants as augmentation to mood stabilizers. Bipolar Disord. 2001;3:259-265.

47. Rybakowski JK. Bipolarity and inadequate response to antidepressant drugs: clinical and psychopharmacological perspective. J Affective Disord. 2012;136:e13-e19.

48. Bowden CL, Vieta E, Ice KS, et al. Ziprasidone plus a mood stabilizer in subjects with bipolar I disorder: a 6-month, randomized, placebo-controlled, double-blind trial. J Clin Psychiatry. 2010;71: $130-137$.

49. Tohen M, Chengappa KN, Suppes T, et al. Relapse prevention in bipolar I disorder: 18-month comparison of olanzapine plus mood stabilizer v. mood stabilizer alone. Br J Psychiatry. 2004;184:337-345.

50. Vieta E, Suppes T, Eggens I, et al. Efficacy and safety of quetiapine in combination with lithium or divalproex for maintenance of patients with bipolar I disorder. J Affective Disord. 2008;109:251-263.

51. Shahdid M, Walker G, Zorn S. Asenapine, a novel psychopharmacologic agent with a unique receptor signature. J Psychopharmacol. 2009;23: 65-73.

52. Chwieduk CM, Scott LJ. Asenapine: a review of its use in the management of mania in adults with bipolar I diosrder. CNS Drugs. 2011;25:251-267.

53. Weber J, McCormack PL. Asenapine. CNS Drugs. 2009;23:781-792.

54. Meyer JM. Pharmacotherapy of psychosis and mania. In: Brunton LL, Blumenthal D, Murri N, Hilal-Dandan R, editors. Goodman and Gilman's the Pharmacological Basis of Therapeutics, 12th ed. New York: McGraw-Hill; 2012. 
55. Lieberman JA, Stroup TS, McEvoy JP, et al. Effectiveness of antipsychotic drugs in patients with chronic schizophrenia. $N$ Engl J Med. 2005;353:1209-1223.

56. McIntyre RS, Wong R. Asenapine: a synthesis of efficacy data in bipolar mania and schizophrenia. Clin Schizophrenia Relat Psychoses. 2012;5: 217-220.

57. Bartlett JA, Maarschalk KV. Understanding the oral mucosal absorption and resulting clinical pharmacokinetics of asenapine. AAPS PharmSciTech. 2012;13:1110-1115.

58. Gerrits M, de Greef R, Peeters P. Effect of absorption site on the pharmacokinetics of sublingual asenapine in healthy male subjects. Biopharm Drug Dispos. 2010;31:351-357.

59. Panagides J, McIntyre RS, Alphs L, et al. Asenapine in acute mania: a randomized, double-blind, placebo- and olanzapine-controlled trial. Biol Psychiatry. 2007;61(Suppl 8):222S-223S.

60. McIntyre RS, Cohen M, Zhao J, et al. A 3-week, randomized, placebocontrolled trial of asenapine in the treatment of acute mania in bipolar mania and mixed states. Bipolar Disord. 2009;11:673-686.

61. McIntyre RS, Cohen M, Zhao J, et al. Asenapine in the treatment of acute mania in bipolar I disorder: a randomized, double-blind, placebocontrolled trial. J Affective Disord. 2010;122:27-38.
62. McIntyre RS, Cohen M, Zhao J, et al. Asenapine versus olanzapine in acute mania: a double-blind extension study. Bipolar Disord. 2009;11: 815-826.

63. Baruch Y, Tadger S, Plopski I, Barak Y. Asenapine for elderly bipolar manic patients. J Affective Disord. 2013;145:130-132.

64. Szegedi A, Calabrese J, Stet L, et al. Asenapine as adjunctive treatment for acute mania associated with bipolar disorder. Results of a 12-week core study and 40-week extensiion. J Clin Psychopharmacology. 2012;32: 46-55.

65. McIntyre RS, Cohen M, Zhao J, et al. Asenapine for long-term treatment of bipolar disorder: a double-blind 40-week extension study. J Affective Disord. 2010;126:358-365.

66. De Hert M, Yu W, Detraux J, et al. Body weight and metabolic adverse effects of asenapine, iloperidone, lurasidone and paliperidone in the treatment of schizophrenia and bipolar diosrder: a systematic review and exploratory meta-analysis. CNS Drugs. 2012;26:733-759.

67. Peeters P, Bockbrader H, Spaans E, et al. Asenapine pharmacokinetics in hepatic and renal impairment. Clin Pharmacokinet. 2011;50: $471-481$.

68. Henry JM, Fuller MA. Asenapine: a new antipsychotic option. J Pharm Pract. 2011;24:447-451.
Neuropsychiatric Disease and Treatment

\section{Publish your work in this journal}

Neuropsychiatric Disease and Treatment is an international, peerreviewed journal of clinical therapeutics and pharmacology focusing on concise rapid reporting of clinical or pre-clinical studies on a range of neuropsychiatric and neurological disorders. This journal is indexed on PubMed Central, the 'PsycINFO' database and CAS.

\section{Dovepress}

The manuscript management system is completely online and includes a very quick and fair peer-review system, which is all easy to use. Visit http://www.dovepress.com/testimonials.php to read real quotes from published authors. 